\title{
INVESTIGATION OF MECHANICAL PROPERTIES FOR HYBRID ALUMINUM METAL MATRIX COMPOSITE
}

\author{
Kannan $\mathrm{S}^{\# 1}$, Arun S ${ }^{* 2}$, Arun kumar D \#3 \\ Department of Mechanical Engineering, Jeppiaar Institute of Technology \\ Chennai, India \\ ${ }^{1}$ kannansrnvsn@gmail.com, ${ }^{2}$ arunpdc@gmail.com, ${ }^{3}$ arundcj@gmail.com
}

\begin{abstract}
Aluminium base material combined to other metal composite has been attempted many researchers in the modern era. In this research silicon carbide reinforced metal with aluminium $(\mathrm{Al}+\mathrm{SiC})$ and molybdenum di sulfide $\left(\mathrm{Al}+\mathrm{SiC}+\mathrm{MoS}_{2}\right)$. Reinforced metal fabricated by stir casting process and then various investigations like microscopic, hardness, tensile, ear test, impact test, bending test are used to analyse the mechanical properties for various applications. The result shows, the prepared material $(\mathrm{Al}+\mathrm{SiC})$ and $\left(\mathrm{Al}+\mathrm{SiC}+\mathrm{MoS}_{2}\right)$ are compared with each other based on the properties of the material it is taken for suitable applications.
\end{abstract}

Index Terms - Aluminium metal matrix composites, silicon carbide, molybdenum di sulphide, mechanical properties.

\section{INTRODUCTION}

A composite material composed of very small to large contribution of different constituent. One constituent is Matrix Phase, and another is reinforcing phase. Matrix with reinforcing phase are attached for desired characteristics. Metal matrix constituents are very attractive materials, but these properties developed by adding of selected reinforcement. To attain higher performance, efficiency, reliability for light weight purpose along with cost effective Aluminum composites are used for various applications.

Fabrication of liquid state metal matrix composites combine with dispersed phase of metal matrix lead by solidification for greater mechanical properties. Through the observation from published research related to aluminium metal matrix, is good attachment of Sic where it is physically stable at any temperature also good bonding strength, less cost to weight ratio it provides greater thermal conductivity. High demand in low weight aluminium material grow in manufacturing sector with good mechanical properties due to this new aluminium composites are developed in this same. More developed material like $\mathrm{Al} / \mathrm{SiC} / \mathrm{Al}_{2} \mathrm{O}_{3}$ it has been in real applications. Current focus towards the introduction of Sic/Mos2 greater reinforcement comparatively remaining reinforcements. As for greater advantages of MoS2 like high solidification temperature, $\left(200^{\circ}-270^{\circ} \mathrm{C}\right)$ with good hardness (75 HRA or $820 \mathrm{HV}$ ) and greater modulus of rigidity $\left(460 \times 10^{3} \mathrm{GPa}\right) . \mathrm{MoS}_{2}$ composition reveals that it stable in liquification, so it avoids the chances of formation of brittle structure. SiC impacts the reduction of $24 \%$ weight for any metals whereas constant mechanical properties.

\section{EXPERIMENTAL WORK}

In the first specimen reinforcement of silicon carbide ( $\mathrm{SiC}$ ) has chosen. Molybendinum die sulfide reinforcement is taken as a second specimen aluminium 6082 is metal matrix phase both silicon carbide and molybdenum die sulfide metal matrix weight percentage is $10 \%$. To remove hydrogen oxide and other contained gases silicon carbide preheated to $1000^{\circ} \mathrm{C}$ at the duration of 2 hour to obtain wettability. Molybdenum die sulfide is preheated upto $200^{\circ} \mathrm{C}$. A matrix melt completely when furnace temperature raise to $750^{\circ} \mathrm{C}$ in this preheated stage silicon carbide of 2 grams, and manganese of $1 \mathrm{gms}$ added to improve wettability. Stirring process carried out at 400 rpm of average speed of 20 mins. In gravity casting method molten metal is filled into the cavity like that molybdenum die sulfide reinforced is fabricated. Microscope is used to observe structure of specimen Vickers hardness testing machine to measure the hardness of the specimen. Universal testing machine carried out tensile strength of the specimen, impact test method used to find out impact strength of the material as per ASTM standard. 


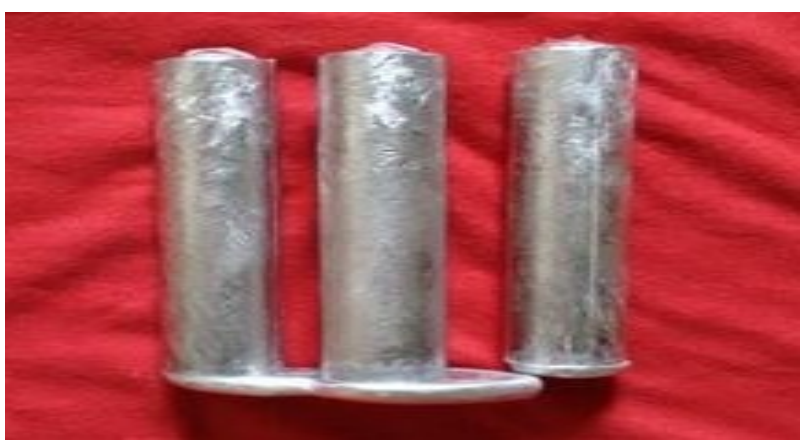

Fig 1. Prepared test specimen

\section{A. Microstructural study}

The optical structure of $\mathrm{Al}-\mathrm{SiC}-\mathrm{MoS}_{2}$ metal matrix compositions are silicon $-1.48 \%$, iron $-0.337 \%$, copper-0.028\%, manganese- $0.724 \%$, magnesium $-0.35 \%$, zinc- 0.095 , chromium $-0.005 \%$, titanium- $0.022 \%$ remaining aluminium contains 96.86\%. the uniform distribution of metal matrix of silicon carbide and molybdenum di sulfide morphological was proved by microstructural analysis. In this observation around silicon carbide reinforcement observed as a cluster when improved weight rate of molybdenum di sulfide leads to the porosity and form the cluster at the weight rate of $\mathrm{MoS}_{2}$.

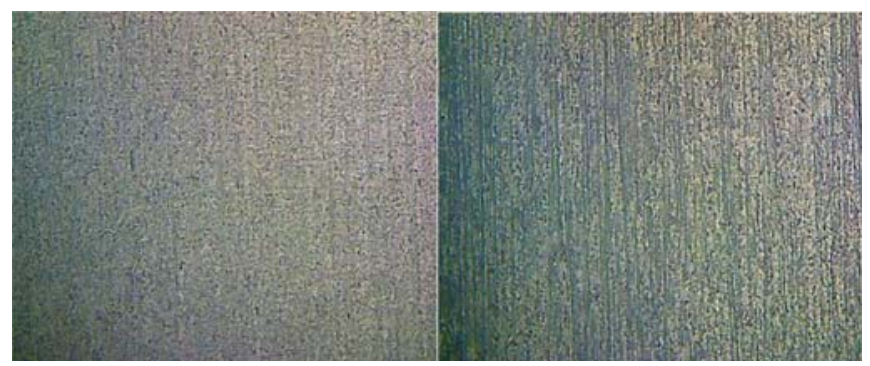

SAMPLE 1 AA6082

SAMPLE 2 AA6082+SiC

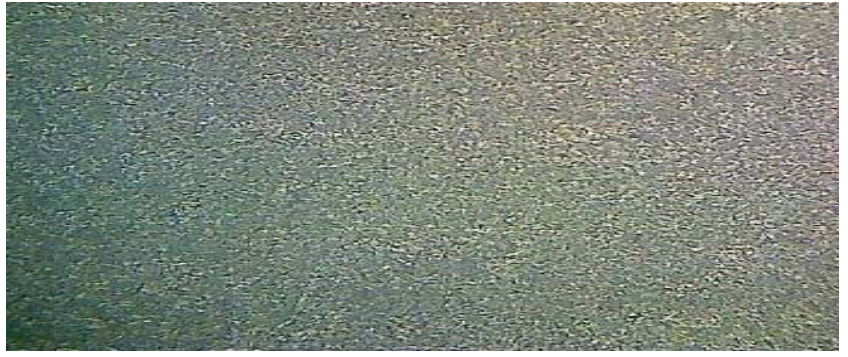

SAMPLE 3 AA6082+SiC $+\mathrm{MoS}_{2}$

Fig 2. Microstructure of sample 1,2, \& 3

\section{B. Hardness Test}

From Vickers hardness test the hardness value of AA6082 is 105, the reinforcement specimen AA $6028+\mathrm{SiC}+$ $\mathrm{MoS}_{2}$ hardness value obtained 72. Due to crystal formation hardness value decreases when $\%$ of $\mathrm{MoS}_{2}$ with leads to porosity. So high amount of reinforcement reduce hardness value in metal matrix composite.

TABLE I. HARDNESS TEST RESULT

\begin{tabular}{|l|l|l|}
\hline S. No & Specimen & Hardness \\
\hline 1 & AA6082 & 105 \\
\hline 2 & AA6082 $+\mathrm{SiC}$ & 116 \\
\hline 3 & AA6082 $+\mathrm{SiC}+\mathrm{MoS}_{2}$ & 72 \\
\hline
\end{tabular}




\section{Tensile Test}

From universal testing machine the tensile strength value taken for AA6082 specimen, AA6082 with silicon reinforcement and AA6082 with silicon and molybdenum disulfide reinforcement. Due to addition of $\mathrm{MoS}_{2}$ tensile strength is reduced because of excess cluster formation makes the porosity in microscope structure of silicon carbide particles surrounded by $\mathrm{MoS}_{2}$ particles it affect interfacial bonding due to lack of aluminium metal matrix.

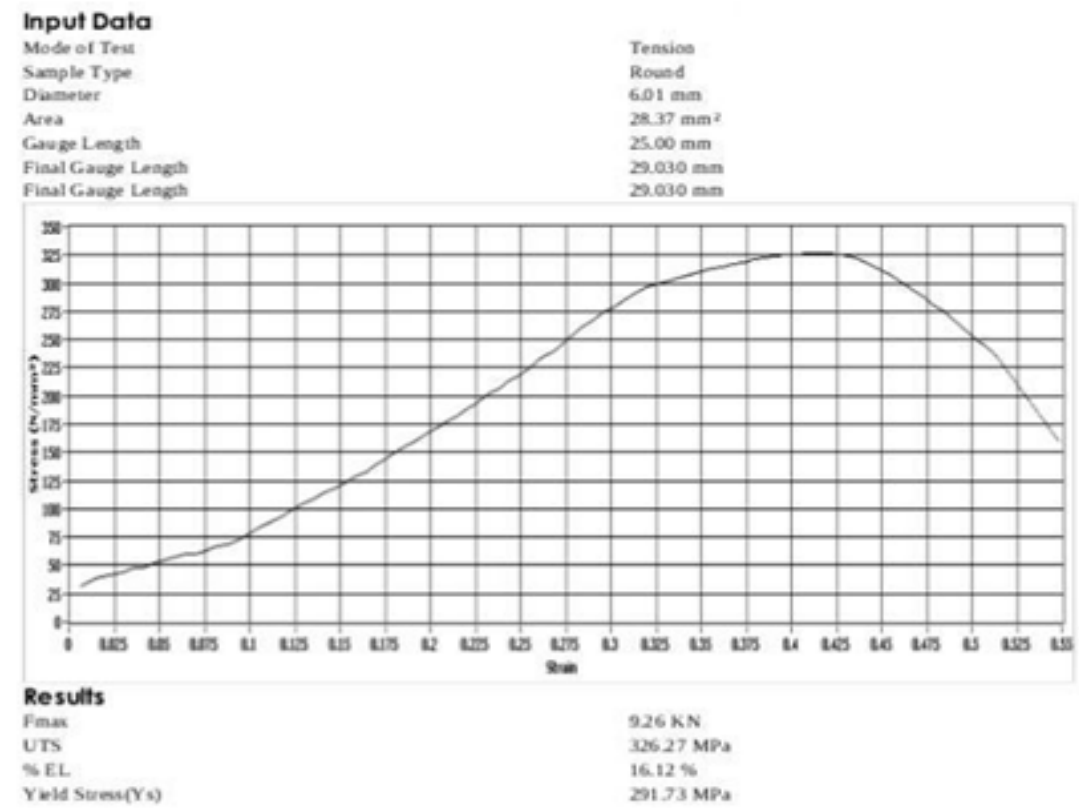

Fig 3. AA6082 Tensile Test Result

To increase the tensile strength properties holding temperature, impeller position in the melt, size of impeller and speed of stirring are key factors.

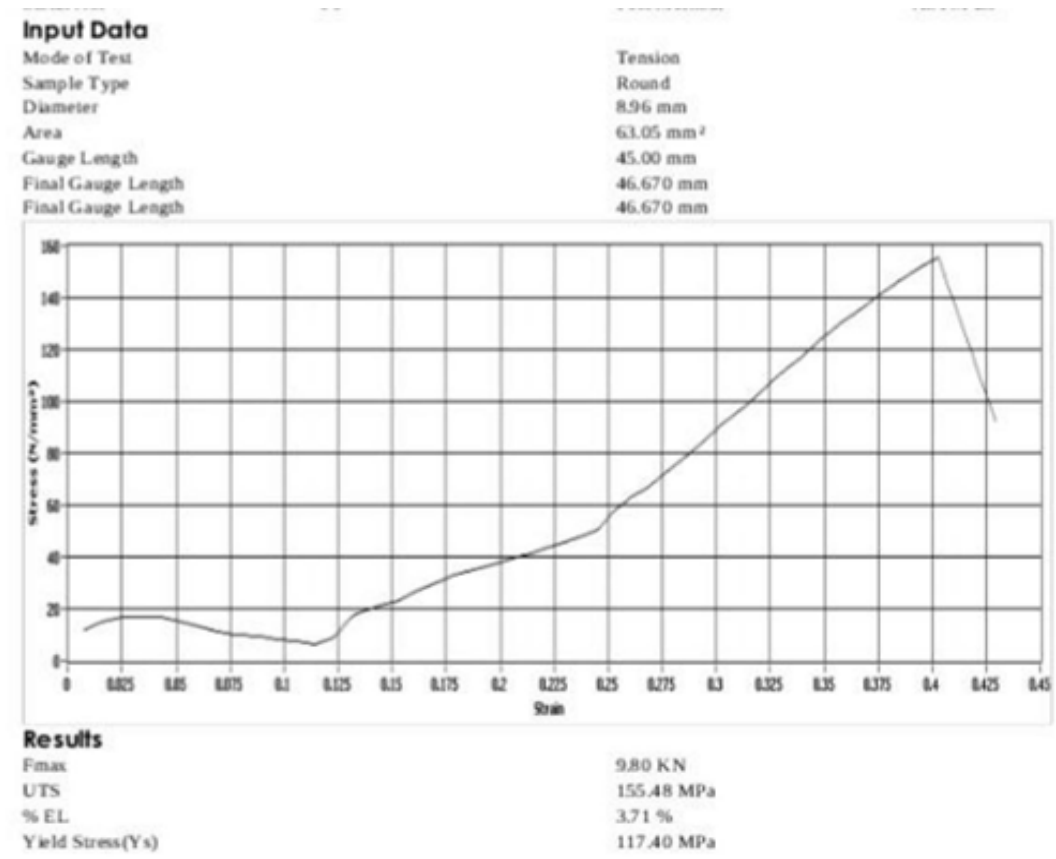

Fig 4. AA6082 + SiC - specimen Tensile Test Result 


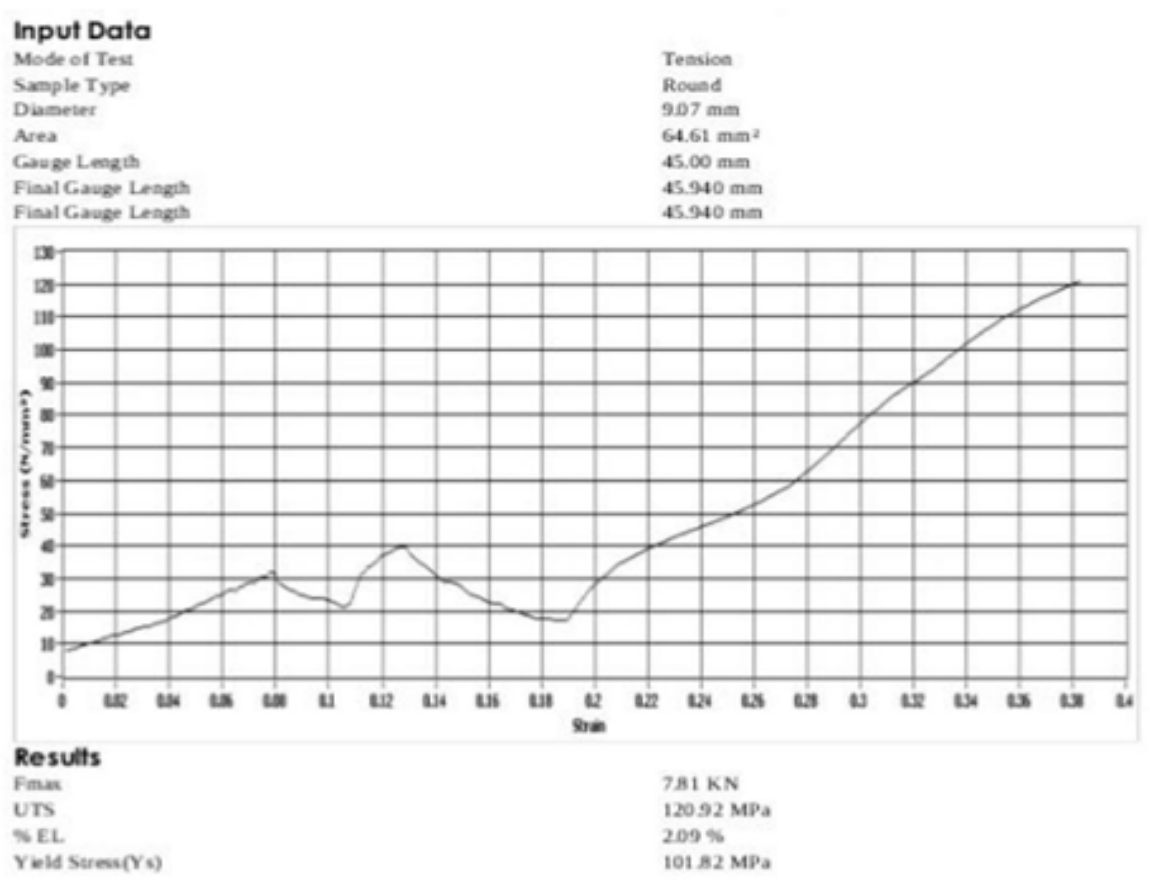

Fig 5. AA6082 $+\mathrm{SiC}+\mathrm{MoS}_{2}-$ specimen Tensile Test Result

TABLE III. TENSILE STRENGTH VALUE OF AA6082, AA6082 + SIC AND AA6082 + SIC + $\mathrm{MOS}_{2}$

\begin{tabular}{|l|l|l|l|l|}
\hline S. No & Specimen & $\begin{array}{l}\text { Tensile Strength } \\
\text { (MPa) }\end{array}$ & \% of elongation & $\begin{array}{l}\text { Yield strength } \\
\text { (MPa) }\end{array}$ \\
\hline 1 & AA6082 & 326.27 & 16.32 & 291.23 \\
\hline 2 & AA6082 $+\mathrm{SiC}$ & 155.48 & 3.71 & 117.40 \\
\hline 3 & AA6082 $\mathrm{SiC}+\mathrm{MoS}_{2}$ & 120.92 & 2.09 & 101.82 \\
\hline
\end{tabular}

\section{Analysis of wear test}

Wear test experiments runs on one hour due to addition of MoS2 content wear resistance value increases SiC wear values attains as $125 \mathrm{~m}$ MoS2 is $96 \mathrm{~mm}$.

\section{E. Analysis of Impact test}

Impact value of aluminium carbide reinforced material is 4 joules when added the MoS2 reinforced metal is 6 joules so, when MoS2 adding with silicon carbide in base metal attains better impact strength.

\section{F. Analysis of Bending test}

Bending test used to find the ductility property of the material sample of silicon carbide bending test results $60.4 \mathrm{KN}$ and sample of $\mathrm{MoS}_{2}$ shows $60.94 \mathrm{KN}$. 


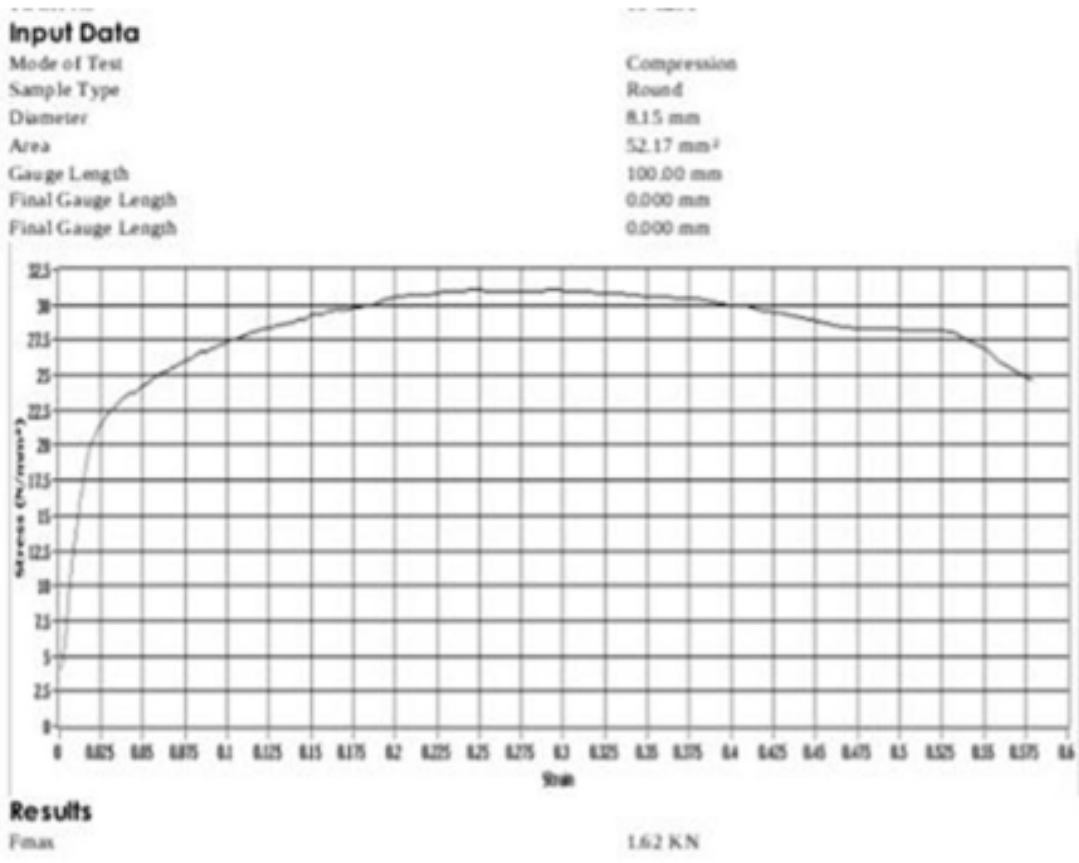

Fig 6. AA6082 - specimen Bending Test

\section{Input Data}

$\begin{array}{ll}\text { Mode of Test } & \text { Conpresuioe } \\ \text { Sample Type } & \text { Round } \\ \text { Diameler } & 21.54 \mathrm{~mm} \\ \text { Arez } & 364.40 \mathrm{~mm}^{2} \\ \text { Gave Length } & 100.00 \mathrm{~mm} \\ \text { Final Gauge Length } & 0.000 \mathrm{~mm} \\ \text { Final Gauge Lengit } & 0.000 \mathrm{~mm}\end{array}$

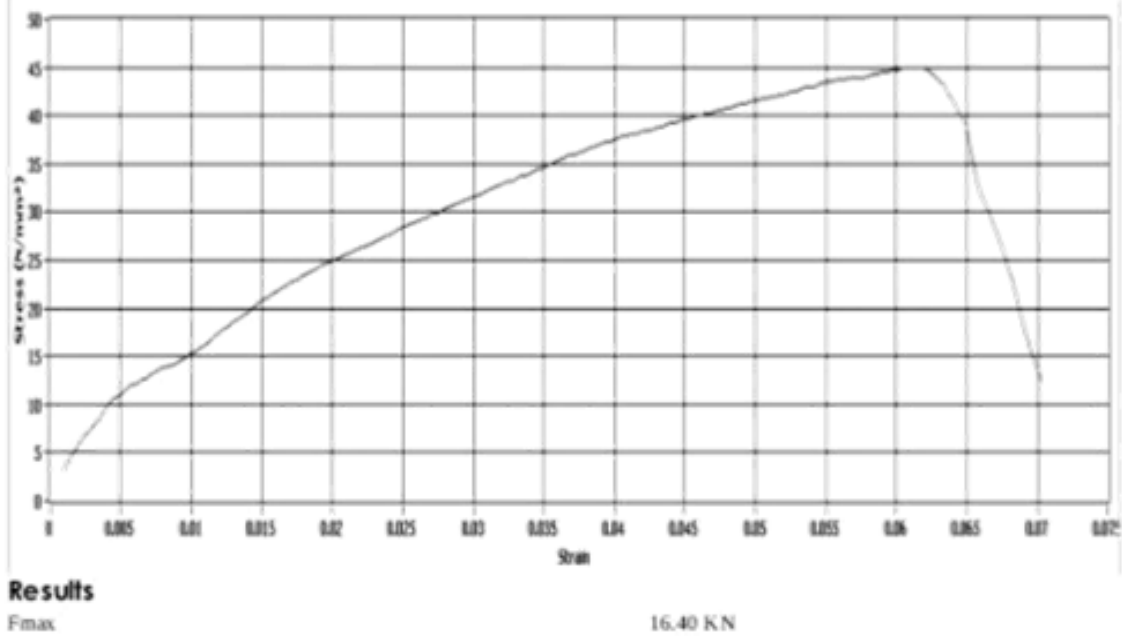

Fig 7. AA6082 + SiC - specimen Bending Test 


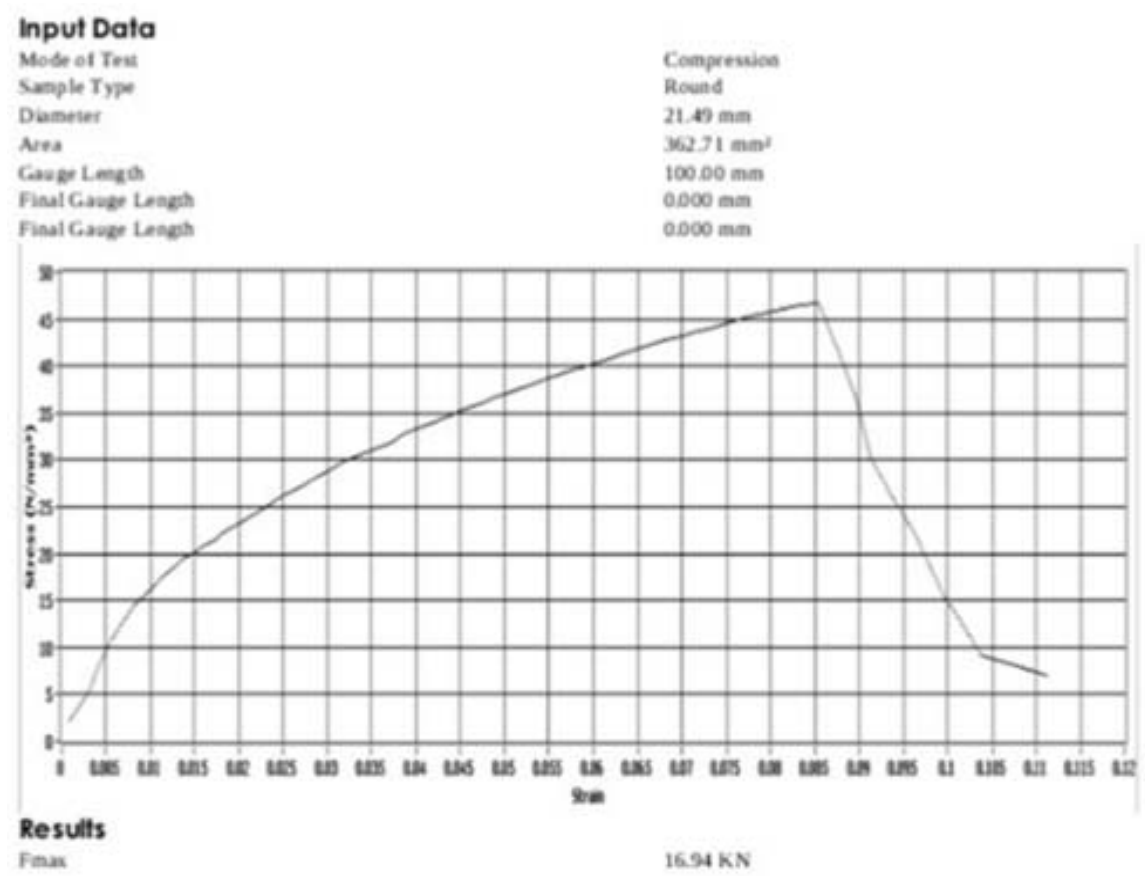

Fig 8. AA6082 $+\mathrm{SiC}+\mathrm{MoS}_{2}-$ specimen Bending Test

\section{CONCLUSION}

From the project related to the Aluminum alloy metal matrix Composite material we have concluded that, the pure aluminum mixed with sum other material by stir casting fabrication procedure. That the result show

1. Analysis of microscopic represents the availability of metal matrix silicon carbide and $\mathrm{MoS}_{2}$. when increase the weight percentage of $\mathrm{MoS}_{2}$ reinforcement makes formation of cluster that increasing better mechanical properties than reducing the weight and cost.

2. Based on increase of $\mathrm{MoS}_{2}$ affects Hardness value and create porosity, The Hardness of the composite formed by stir casting is better than the base metal.

3. In tensile test experiment, tensile strength value decreases due to formation of cluster and porosity.

4. Hybrid aluminium metal matrix $\mathrm{MoS}_{2}$ proves increase the wear resistance and abrasive property.

5. In bending test silicon carbide with molybdenum di sulfide shows better impact value than silicon carbide reinforcement.

6. In bending test experiment shows $\mathrm{MoS}_{2}$ has higher ductility property than $\mathrm{SiC}$ reinforcement and Aluminium base metal.

\section{ACKNOWLEDGMENT}

We would like to very thankful our Managing Director of Jeppiaar Institute of Technology for the strong support to do the research activities and lab utilisation.

\section{REFERENCES}

[1] Ramesh B T, Vinayak Koppad, Hemanth Raju T, "Fabrication of Stir casting Setup for Metal Matrix Composite” International Journal for Scientific Research \& Development, Vol. 5, Issue 06, 2017.

[2] Srinivasa.K, Devaraj.M.R, Yathisha.N, Manjunath.H.S, "Microstructure analysis and wear behaviour of al based metal matrix composite reinforced with ceramic particles” International journal of Research in Engineering and Technology, Volume 3, Issue 9, 2014.

[3] Mitesh Kumar1, Ashok Kumar Mishra2, "Mechanical Behavior of Al 6063/ MOS2/ Al2O3 Hybrid Metal Matrix Composites", International Journal of Scientific and Research Publications, Volume 4, Issue 12, December 2014.

[4] Suresh, K. R., Niranjan, H. B., Jebaraj, P. Martin, Chowdiah, M. P., “Tensile and wear properties of aluminum composites” Published by Elsevier Science B. V., vol. 255, pp. 638 - 642, 2003.

[5] Chennakesava, Reddy A., and Zitoun Essa, "Matrix Al-alloys for silicon carbide particle reinforced metal matrix composites" Indian Journal of Science and Technology, Vol. 3, No. 12, pp. 1184-1187, 2010.

[6] K.Umanath, "Analysis of dry sliding wear Behavior of Al6061/SiC/Al2O3 hybrid metal matrix composites”, Composites Part B: Engineering, Volume 53, October 2013, Pages 159-168.

[7] Vinoth, K. S., Subramanian, R., Dharmalingam, S., Anandavel, B., 2012, "Mechanical and tribological characteristics of stir-cast Al-Si10Mg and self-lubricating Al-Si10Mg/MoS2 composites” Materials and technology, Vol.46, 5, pp. 497- 501 


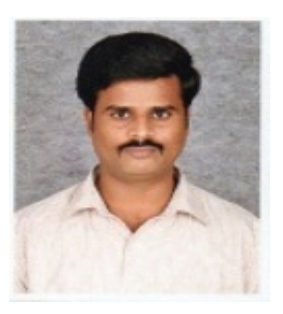

\section{AUTHOR PROFILE}

Mr. S .KANNAN is working as Assistant Professor in Department of Mechanical Engineering, He has 8.5 years of Experience in teaching. He received his B.E (MECHANICAL ENGINEERING) degree first class from Thiruvalluvar college of Engineering and Technology, Anna University, M.E(ENGINEERING DESIGN) first class from Anna University coimbatore. He joined in Jeppiaar Institute of Technology from July 2014. He is currently pursuing his Ph.D in Anna University in the domain of "Additive Manufacturing”.

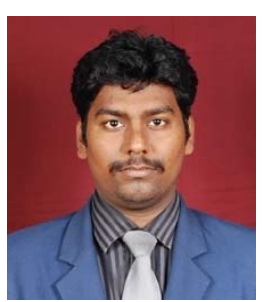

Mr. S.ARUN graduated B.E. in Mechanical Engineering at SKP Engineering College, Tiruvannamalai, and completed his Master's in Engineering inn Product Design \& Commerce from PSG College of Technology, Coimbatore. He is currently pursuing his Ph.D in Anna University in the domain of "Additive Manufacturing". He is an active member in "Additive Manufacturing Society of India (AMSI) .

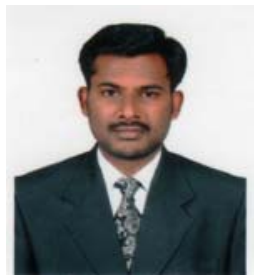

Mr. D. ARUNKUMAR graduated B.E. in Mechanical Engineering at Thanthai Periyar Government Institute of Technology, Vellore, and completed his Master's in Engineering in Engineering Design from Adhiyamaan College of Engineering, Hosur. He is currently pursuing his Ph.D in Anna University in the domain of "Green Energy". $\mathrm{He}$ is an active member in "Indian Society of Technical Education (ISTE). 